\title{
Cognitive Decline in Preclinical Alzheimer's Disease: Amyloid-Beta versus Tauopathy
}

\author{
Colin M. Huber ${ }^{\mathrm{a}, \mathrm{b}}$, Connor Yee ${ }^{\mathrm{a}}$, Taylor May ${ }^{\mathrm{a}}$, Apoorva Dhanala ${ }^{\mathrm{a}}$ and Cassie S. Mitchell ${ }^{\mathrm{a}, *}$ \\ ${ }^{a}$ Department of Biomedical Engineering, Georgia Institute of Technology and Emory University \\ School of Medicine, Atlanta, GA, USA \\ ${ }^{\mathrm{b}}$ Department of Bioengineering, University of Pennsylvania School of Engineering and Applied \\ Sciences, Philadelphia, PA, USA
}

Accepted 6 September 2017

\begin{abstract}
We perform a large-scale meta-analysis of 51 peer-reviewed 3xTg-AD mouse publications to compare Alzheimer's disease (AD) quantitative clinical outcome measures, including amyloid- $\beta(\mathrm{A} \beta)$, total tau, and phosphorylated tau (pTau), with cognitive performance in Morris water maze (MWM) and Novel Object Recognition (NOR). "High" levels of A $\beta$ (A $\beta_{40}$, $\mathrm{A} \beta_{42}$ ) showed significant but weak trends with cognitive decline (MWM: slope $=0.336, \mathrm{R}^{2}=0.149, n=259, p<0.001$; NOR: slope $=0.156, \mathrm{R}^{2}=0.064, n=116, p<0.05$ ); only soluble $\mathrm{A} \beta$ or directly measured $\mathrm{A} \beta$ meaningfully contribute. Tau expression in 3xTg-AD mice was within 10-20\% of wild type and not associated with cognitive decline. In contrast, increased pTau is directly and significantly correlated with cognitive decline in MWM (slope $=0.408, \mathrm{R}^{2}=0.275, n=371, p<<0.01$ ) and NOR (slope $=0.319, \mathrm{R}^{2}=0.176, n=113, p<0.05$ ). While a variety of pTau epitopes (AT8, AT270, AT180, PHF-1) were examined, AT8 correlated most strongly with cognition (slope $=0.586, \mathrm{R}^{2}=0.521, n=185, p<<0.001$ ). Multiple linear regression confirmed pTau is a stronger predictor of MWM performance than $A \beta$. Despite pTau's lower physical concentration than $A \beta$, pTau levels more directly and quantitatively correlate with $3 x T g-A D$ cognitive decline. pTau's contribution to neurofibrillary tangles well after $A \beta$ levels plateau makes pTau a viable treatment target even in late-stage clinical AD. Principal component analysis, which included hyperphosphorylation induced by kinases (pGSK3 $\beta$, GSK3 $\beta$, CDK5), identified phosphorylated ser9 GSK3 $\beta$ as the primary contributor to MWM variance. In summary, meta-analysis of cognitive decline in preclinical $\mathrm{AD}$ finds tauopathy more impactful than $\mathrm{A} \beta$. Nonetheless, complex AD interactions dictate successful therapeutics harness synergy between $A \beta$ and pTau, possibly through the GSK3 pathway.
\end{abstract}

Keywords: 3xTg-AD, amyloid- $\beta$, GSK3, meta-analysis, phosphorylated tau, total tau

\section{INTRODUCTION}

The hallmarks of Alzheimer's disease (AD) pathology are marked by accumulation of extracellular amyloid- $\beta$ (A $\beta)$ plaques in the brain followed by intracellular neurofibrillary tangle (NFT) growth $[1,2] . A \beta$ upregulates the generation of NFTs by increasing glycogen synthase kinase-3 (GSK-3)

\footnotetext{
${ }^{*}$ Correspondence to: Cassie S. Mitchell, PhD, Assistant Professor, Biomedical Engineering, Georgia Institute of Technology and Emory University, 313 Ferst Drive, Atlanta, GA 30332, USA. Tel.: +1 404276 8475; E-mail: cassie.mitchell@bme.gatech.edu.
}

activity, leading to the phosphorylation of tau $[3,4]$. Phosphorylated tau (pTau) begins to self-assemble to form NFTs. A $\beta$ plaques, soluble $A \beta$ oligomers, and NFTs interfere with normal neuronal cell function by disrupting synaptic signaling at neural junctions. Each protein's accumulation leads to neuron damage, eliciting diminished brain mass and cognitive function [5]. pTau is linked to retarding $A \beta$ growth establishing a negative feedback loop where increases in pTau slows rate of $A \beta$ accumulation [3]. As the disease progresses in late stages, pTau continues to form NFTs while $A \beta$ plaque accumulation plateaus. 
Soluble $A \beta$ oligomers, rather than $A \beta$ plaques or soluble $A \beta$ monomers, have emerged and continue to attract attention as the main toxic form of $\mathrm{A} \beta$ [6-8]. These oligomers may continue to accumulate as $A \beta$ plaques plateau, and they may create a crucial link in explaining the connection between $\mathrm{A} \beta$ and pTau.

The removal of $A \beta$ plaques does not influence elimination of NFTs after NFTs have been established in the brain, but early intervention can prevent pTau development $[9,10]$. Therefore, targeted late stage treatments may specifically eliminate $\mathrm{A} \beta$ without impacting pTau levels that have already accumulated, which enables NFTs to continue amplifying cognitive deficits. Comparison of differences in pTau and $A \beta$ levels in treated mice illuminate differences between the proteins' impact on cognitive function. For example, pTau levels were reduced by chemical treatment as $A \beta$ levels continued to increase, yet cognitive function improved [11]. This result implies that there is a quantitative difference between how the two proteins effect cognitive deterioration, and moreover, that decreasing pTau may ultimately be more important than reducing $A \beta$ in the quest to successfully treat AD.

The Amyloid Cascade Hypothesis states that $A \beta$ is the center piece in $\mathrm{AD}$ pathology leading to hyperphosphorylation of tau and numerous neurotoxic pathways causing cell death [12]. Since its inception, $A \beta$ has been the main focus of $A D$ research, but there have been no definitive AD treatments or cures found to date [12]. The only FDA approved treatments are cholinesterase inhibitors, which increase acetylcholine levels to simply suppress the cognitive symptoms of $\mathrm{AD}$, and memantine, which regulates glutamate to elicit neuroprotective effects but only mild cognitive improvement [13]. These drug treatments simply mitigate the cognitive symptoms of $\mathrm{AD}$ without slowing disease progression, and treatments targeting $A \beta$ and $A \beta$ precursors have failed to pass clinical trials to improve patient outcomes [13, 14]. The presence of $A \beta$ is associated with a decrease in cognitive performance; however, the quantitative level of $A \beta$ inconsistently predicts the amount of cognitive decline [15]. Instead, it is suggested that other contributors, such as the hyperphosphorylation of tau, are the functional cause of degeneration after the initial onset of $\mathrm{AD}$ [5].

The present study compares the effects of $A \beta$ and pTau levels on cognitive performance in the Morris water maze (MWM) and Novel Object Recognition (NOR) through a large-scale meta-analysis of 3xTgAD mouse model experiments. The triple-transgenic mouse model (3xTg-AD) of AD expresses tangle and plaque pathology as well as synaptic dysfunction [16]. The 3xTg-AD mouse model pathology resembles human patients, and it has similar total tau levels in the cerebrospinal fluid unlike other tau pathology models (P301L and Tg4510) [17, 18]. A $\beta$ deposits first appear by 6 months of age while the first definitive detection of pTau occurs around 12 months of age; therefore, cognitive deficits due to tau pathology are expected to begin between 8 and 12 months of age $[16,18,19]$. The MWM reliably reflects how degradation of the hippocampus, striatum, basal forebrain, cerebellum, and neocortical areas affect cognitive function [20]. Meta-analysis was focused on correlations between cognitive ability measured by MWM or NOR and A $\beta$ or pTau levels. The primary goal was to determine which clinical outcome measures most directly correlate with statistically significant cognitive decline in 3xTg-AD mice. Specific analyses were conducted to analyze the different $A \beta$ forms and $p$ Tau epitopes. We also consider the interactions between pTau and $A \beta$ to identify promising research targets for understanding the intertwining pathology of $\mathrm{AD}$.

\section{METHODS}

\section{Systematic review process}

We perform a systematic review, which quantitatively analyzes studies in a consistent manner to provide an over-arching view of a field's aggregated work. First, a series of database searches identified peer-reviewed publications that are likely to meet the study's criteria. These publications are then examined individually to determine whether they meet the inclusion criteria (see below). All quantifiable experimental data from figures and tables are extracted into an organized database in a process overseen by stringent quality control teams, resulting in transcription accuracy greater than $98.8 \%$ [21]. Comparable data are compiled to assess overall trends.

\section{Inclusion criteria}

Key term searches in PubMed were used to identify publications likely to meet the inclusion criteria. Search terms included "Alzheimer's Disease", "3xTg-AD", "amyloid- $\beta$ ", "tau", "phosphorylated tau", and "glycogen synthase kinase-3" as well as numerous synonymous combinations, variations, and abbreviations of these terms. For inclusion, peerreviewed scientific studies must contain quantifiable 
Table 1

Breakdown of data pools and corresponding included peer-reviewed data sources and mice sample sizes. The bracketed numbers in the study citations column correspond to the references

\begin{tabular}{llrr}
\hline Data Pool & Sources (Citations) & Sources (N) & Mice (n) \\
\hline MWM versus Total A $\beta$ & {$[33,34,39-42,44,47,50,59,60,62,63,65,67-69,76-80]$} & 22 & 259 \\
MWM versus Soluble A $\beta_{40}$ & {$[33,34,39-41,47,60-63,68,69,72,77,78]$} & 15 & 148 \\
MWM versus Soluble $A \beta_{42}$ & {$[33,34,39-41,50,60,61,63,68,69,72,77-79]$} & 16 & 148 \\
MWM versus Insoluble A $\beta_{40}$ & {$[33,34,39-41,47,60-63,68,69,72,77,78]$} & 15 & 144 \\
MWM versus Insoluble A $\beta_{42}$ & {$[33,34,39-41,50,60,62,63,68,69,72,77-79]$} & 15 & 144 \\
MWM versus Total Tau & {$[19,33,39,41,47,49,53,54,57,60-63,65,69,72,76,78,79,82]$} & 20 & 152 \\
MWM versus pTau & {$[19,33,39,41,47,49-51,53,54,58-60,62,63,65,67-69,71-81]$} & 30 & 371 \\
MWM versus AT8 pTau & {$[19,50,53,58,59,65,67-69,71-76]$} & 15 & 185 \\
MWM versus AT270 pTau & {$[19,50,51,60,62,65,76,77]$} & 88 \\
MWM versus PHF-1 pTau & {$[33,39,47,49,60,63,65,72,73,78,81]$} & 11 & 7 \\
MWM versus AT180 pTau & {$[19,44,54,60,65,77,80]$} & 16 & 48 \\
NOR versus Total A $\beta$ & {$[19,32,34,36,37,41,43,44,46,56,57,59,61,65,66,82]$} & 9 \\
NOR versus Total Tau & {$[19,32,34,41,44,46,57,59,82]$} & 116 \\
NOR versus pTau & {$[19,32,34,38,43,46,57,59,61,78,82]$} & 85 \\
pGSK3 $\beta$ PCA & {$[19,32-40,42-46,48-78,80-82]$} & 49 & 113 \\
TOTALS & {$[19,32-82]$} & 51 & 507 \\
\hline
\end{tabular}

data for either pTau or $A \beta$ levels and data for either MWM escape latency or NOR. Only papers utilizing the 3xTg-AD treated and control groups and published in English were included. Resultant searches led to the construction of a transcribed database [21] of 3,102 peer-reviewed preclinical AD articles that were assessed for inclusion. A total of 51 peerreviewed journal articles met the required criteria for final inclusion (see Table 1).

\section{3xTg-AD mouse model}

The 3xTg-AD mouse model is a complex model with transgenic amyloid- $\beta$ protein precursor (AßPP), presenilin-1 (PS1M146V), and tauP301L gene replacements [18]. As in human AD pathology, both $\mathrm{A} \beta$ and tau formation show age- and regiondependence with $A \beta$ plaques forming before the accumulation of NFTs [22]. 3xTg-AD mice have concentrations closer to human levels than P301L and $\mathrm{Tg} 4510$ transgenic AD mouse models [17]. A $\beta$, total tau, and pTau measurements were used from the mouse hippocampus (see Data Sources), which is the most direct morphological site of learning ability and memory. While other neuroanatomical sites are still of interest, the overwhelming preponderance of data is recorded from the hippocampus. Functional cognitive deficits appear as early as 4 months of age in the $3 \times \mathrm{Tg}-\mathrm{AD}$ mice, a timeline that aligns with the formation of intracellular deposits of $A \beta$ in the hippocampus [23]. Both $A \beta$ and pTau accumulate in significant levels in the brain after 8-12 months to contribute to cognitive deficits. $3 \times \mathrm{Tg}$-AD is one of the few models containing both $\mathrm{A} \beta$ and $\mathrm{pTau}$ pathologies in transgenic form, which allows for manipulation of protein development through treatment utilizing numerous pathways across a full lifespan. The development of $\mathrm{AD}$ in $3 \mathrm{xTg}-\mathrm{AD}$ mice also mimics that in humans, so accumulation of pTau can be influenced upstream by $A \beta$; therefore, $A \beta$ treatments early in life can be studied for impact on pTau. The complex pathology in $3 x \mathrm{Tg}$-AD mice enables quantitative comparisons of $A \beta$ and NFTs, making it an ideal and unique model for full $\mathrm{AD}$ assessment.

\section{Morris Water Maze}

The MWM, which tests spatial memory, was used as the primary measure of cognitive performance. The MWM is the de facto industry standard for cognitive tests for mouse models and was chosen because of its prevalence in AD experimental studies. A mouse is placed into a pool of water and trained to search for a visible platform in an open, cold $\left(13^{\circ} \mathrm{C}\right)$ bath $[24,25]$. After one day of training with the platform visible above water, the mouse is again placed in the maze with the platform hidden below the water and uses visual cues outside of the bath to find the platform location. Training with the hidden platform continues four times a day for five to seven days. The time it takes for the mouse to find the platform is measured as the mouse's escape latency [26]. Escape latency data from day five was analyzed because it most highlights differences in learning within the standard practice of five days of training. Moreover, overtraining (too many trials per day or too many days of training) can result in all mice performing at a disproportionately high level and thus, preventing discernable 
quantitative learning differences [27]. The first two trials on day one serve as a control between mice for swimming performance and ability; mouse groups should not significantly differ on day one escape latency [25].

\section{Novel Object Recognition}

Due to the perceived limitations of the MWM (e.g. mice are less suited to the task than rats, the stress caused by cold water may affect the results, it only tests spatial memory, etc.), NOR was used as a second measure of cognitive performance [28, 29]. NOR introduces mice to a new object and a familiar object to which the mouse had previously been exposed. Memory is then tested by the relative amount of time spent exploring the new object based on remembering the familiar object [30]. We chose recognition index (time spent exploring the novel object/ total time exploring) as the standard measurement for NOR. In cases where only percent time spent with novel object or discrimination index was provided, recognition index was calculated. NOR avoids stress on the mice and other factors such as swimming capability inherent to the MWM. However, the disadvantage of the NOR compared to the MWM is the inability to differentiate between the spatial and non-spatial conditions of the task [31].

\section{Data sources}

The $3 \times \mathrm{Tg}$-AD mouse model was developed in the Laferla Laboratory [16] and later commercially made available by the Jackson Laboratory. As such, most

(A)

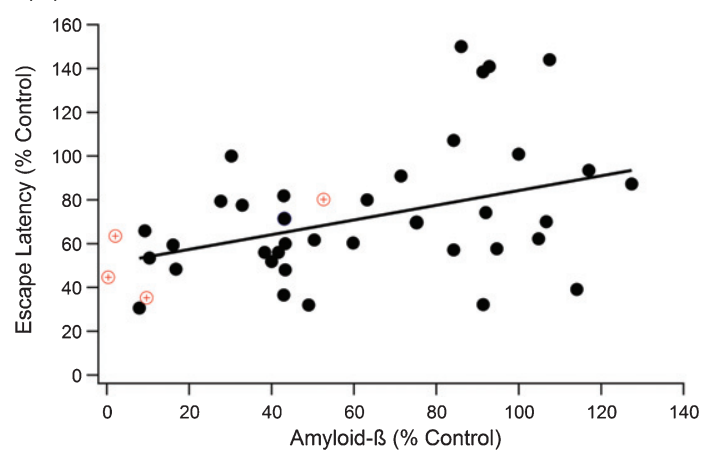

studies cited their mouse source as a gift from a colony originating from the Laferla laboratory or as purchased from the Jackson Laboratory. The included studies range from the years 2007 to 2016, with the majority from 2014 to 2016 . When stated, the mouse background was listed as 129/C57BL6. Supplementary Table 1 lists all included studies and their corresponding year and available source information. Nonetheless, full reference citations for the included studies, broken down by their inclusion in each subanalysis, is listed in Table 1 of the main article. Neuroanatomical location of source data is limited to the hippocampus, which ensured sample sizes of sufficient statistical power.

\section{Data normalization}

All data was normalized against untreated control 3xTg-AD mice within the same study to achieve a consistent baseline. In a single peer-reviewed article, muscarinic $\mathrm{M}_{1}$ receptor deficient $\left(\mathrm{M}_{1} \mathrm{R}^{-/-}\right)$mice bred with $3 \mathrm{xTg}-\mathrm{AD}$ were taken as the experimental group rather than a treatment to $3 \mathrm{xTg}$ - $\mathrm{AD}$ mice for the other articles in this study; data was still normalized to untreated control 3xTg-AD mice [32]. A $\beta$ and pTau were rarely measured in wild type mice, so wild type mice could not serve as the primary control. A few comparisons of untreated wild type mice normalized to untreated $3 \times$ Tg-AD mice are displayed in the Results figures (i.e., Figs. 1 and 4) as red targets. They provide examples of relative differences in escape latency and lower pTau and $\mathrm{A} \beta$ levels in a non-transgenic model compared to the consistent untreated $3 \mathrm{xTg}-\mathrm{AD}$ control. pTau is

(B)

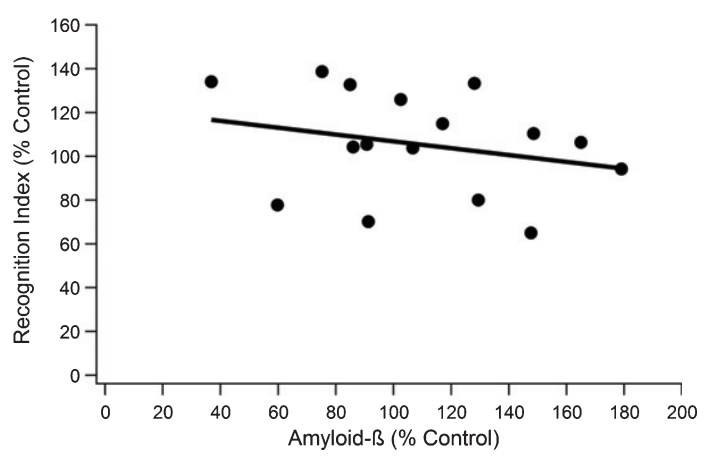

Fig. 1. Increases in A $\beta$ plaque level weakly correlates with decline in performance in both the MWM and the NOR test. A) A positive trend indicates that as $\mathrm{A} \beta$ increases, cognitive performance declines (slope $=0.336, \mathrm{R}^{2}=0.149, n=259, p<0.001$ ). The red target markers provide a visual reference for untreated wild type mouse measurements in comparison to 3xTg-AD control mice. B) NOR correlation results in similar significant, weak trends, where a negative trend indicates decreased cognitive function with increased $A \beta\left(\right.$ slope $=-0.156, R^{2}=0.064$, $n=116, p<0.05)$. 

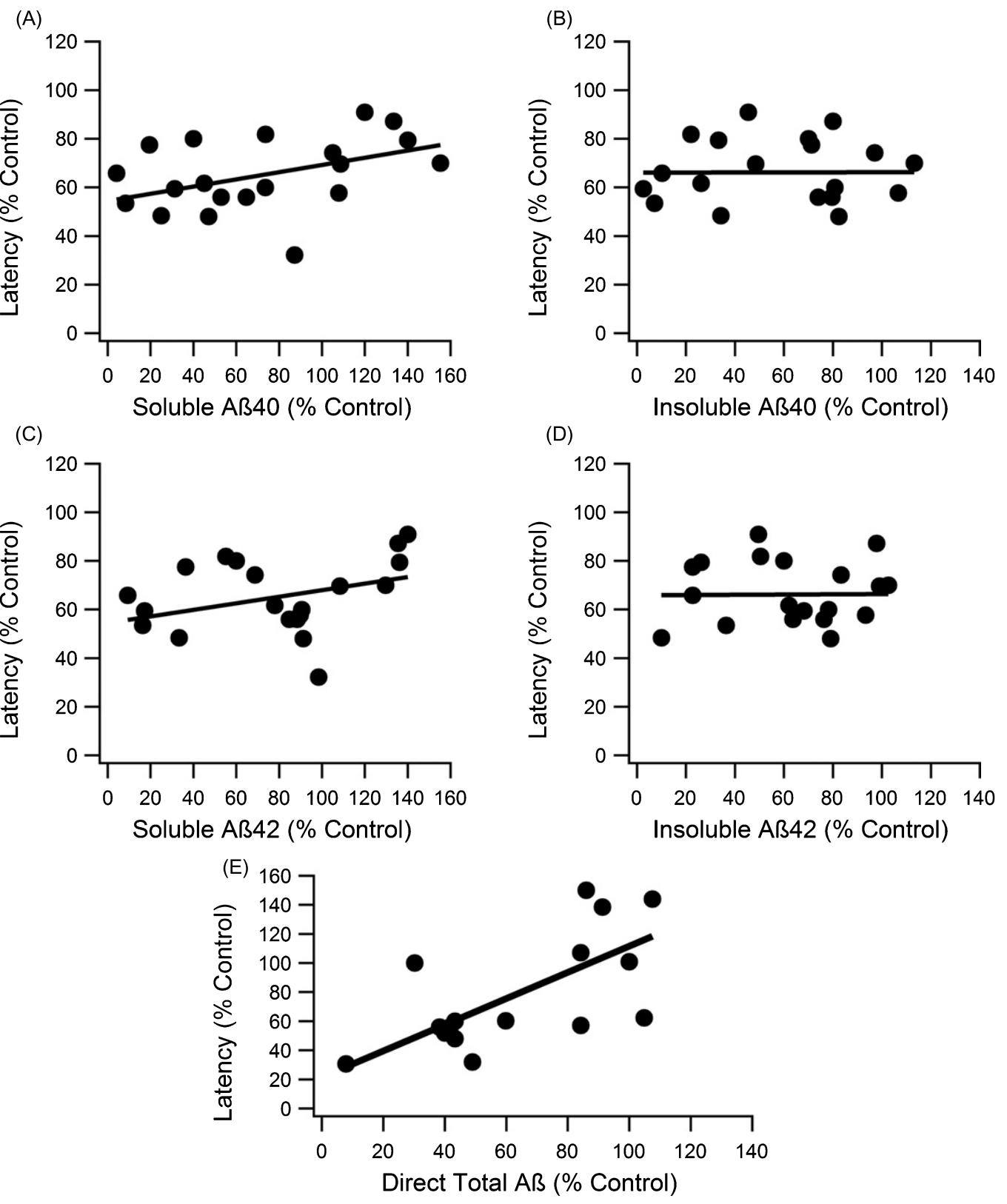

Fig. 2. Correlation analysis of each major $A \beta$ form to MWM escape latency. A, C) The soluble forms of $A \beta$ showed significant correlation with escape latency performance, and the slope of the trend was similar to total $\mathrm{A} \beta$ (slope $=0.148, \mathrm{R}^{2}=0.247, n=148, p<0.001$; slope $=0.135$, $\mathrm{R}^{2}=0.1667, n=148, p<0.001$, for $\mathrm{A} \beta_{40}$ and $\mathrm{A} \beta_{42}$, respectively). $\left.\mathrm{B}, \mathrm{D}\right)$ Neither insoluble $\mathrm{A} \beta_{40}$ nor $\mathrm{A} \beta_{42}$ displayed significant trends with cognitive function (slopes $<0.005, \mathrm{R}^{2}<0.001, n=144, p>>0.05$ ). E) Direct $\mathrm{A} \beta$ had a significant trend with cognitive function (slope $=0.901$, $\left.\mathrm{R}^{2}=0.464, n=93, p<<0.001\right)$.

usually measured in arbitrary units, so a percent control calculation expresses a normalized data value: (Day 5 Escape Latency of treated 3xTg-AD experiment group) / (Day 5 Escape Latency of untreated $3 \times T g-A D$ control group) $\times 100 \%$. Protein level can substitute for escape latency in the example above to attain equivalent percent control values for $A \beta$ and
pTau. There were no significant differences in variance (F-test $p=0.8453$ ) or mean ( $t$-test $p=0.5008$ ) between MWM data normalized to day one compared to the non-normalized counterpart. Day $1 \mathrm{MWM}$ training on a visible platform is consistent for all mice, so escape latency data was not normalized to day 1 to minimize data processing and alteration. 

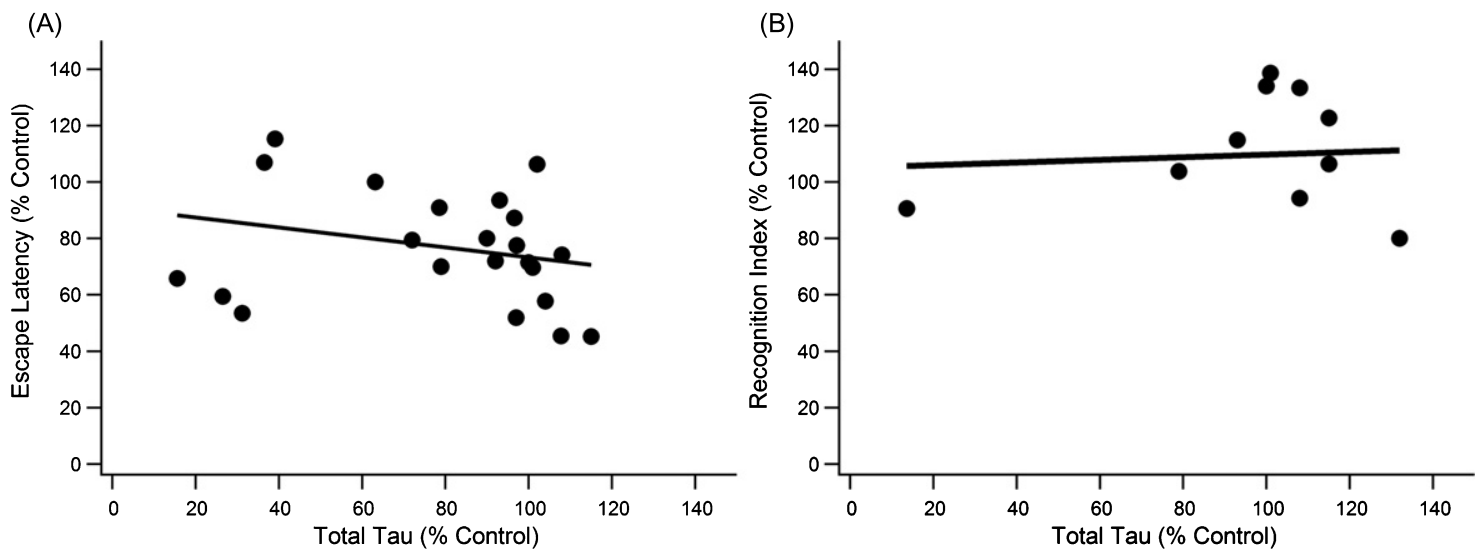

Fig. 3. Total Tau does not significantly correlate with cognitive decline measured by the MWM or NOR. A) There was a weak, significant trend for day five escape latency with total tau levels (slope $=-0.1768 \mathrm{x}, \mathrm{R}^{2}=0.071, n=152, p<0.001$ ). B) Tau levels did not correlate significantly with performance in the NOR test $(n=85, p>>0.05)$.

(A)

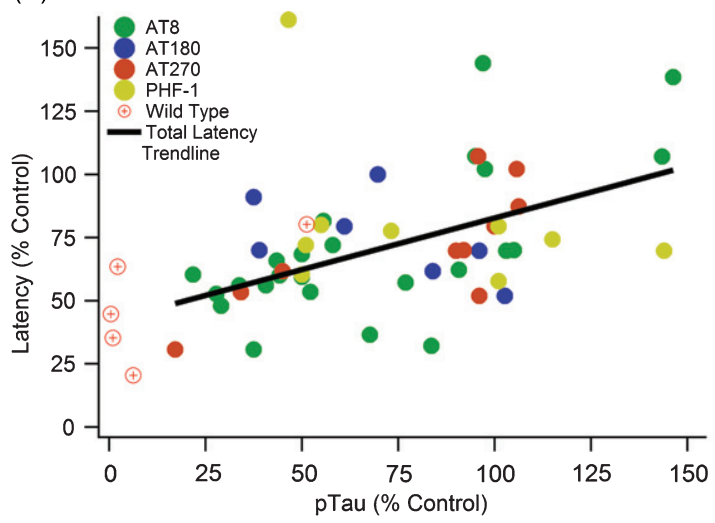

(B)

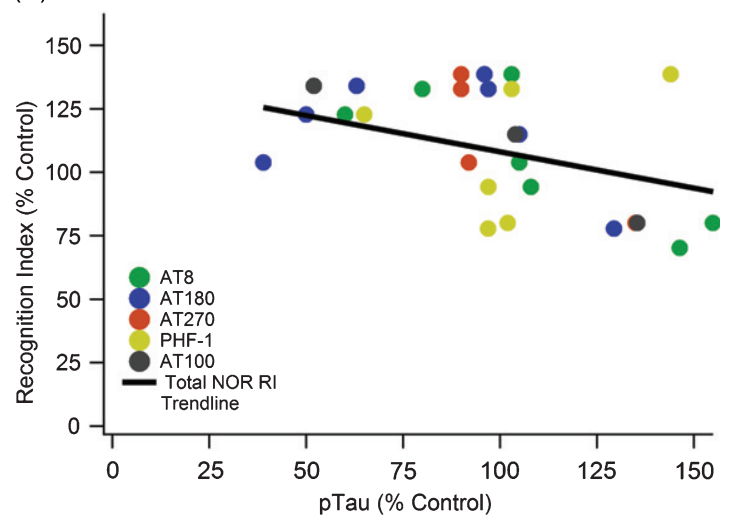

Fig. 4. Increased pTau correlates with cognitive decline in both MWM and NOR cognitive tests. A) A significant positive slope with escape latency indicates cognitive function decreases as pTau levels increase (slope $=0.408, \mathrm{R}^{2}=0.275, n=371, p<<0.01$ ). B) A significant negative slope with NOR indicates cognitive function decreases as pTau levels increase (slope $=-0.3196, \mathrm{R}^{2}=0.176, n=113, p<0.05$ ).

\section{Statistical analysis}

We examined the correlation of escape latency or NOR recognition index against tau, pTau, and $A \beta$ levels by performing a Pearson coefficient correlation analysis at alpha level 0.05 . After determining significance, Pearson coefficient and slope allows comparison of the strength of the correlation. The Igor analytical software (Wavemetrics, Inc.) was used to calculate the line of best fit and the corresponding $\mathrm{R}^{2}$ values. A principle component analysis (PCA) was used to evaluate variance among kinases involved in the phosphorylation of tau; results were generated utilizing the built-in PCA function in MATLAB (The MathWorks, Inc.). A multiple linear regression also directly compared pTau and $A \beta$ in studies that analyzed both protein levels; the MATLAB stepwise function established correlation factors between cognitive performance and protein variables at $\alpha=0.05$ for significance. Clear outliers (9 data points) were eliminated by the Grubb test; graphical depiction and statistical analysis presented in the Results are without outliers.

\section{RESULTS}

This systematic review and meta-analysis compares experimentally assessed cognitive function (e.g., MWM escape latency or NOR recognition index) in 3xTg-AD mice with clinical outcome measures for $A \beta$, total tau, and pTau. A total of 528 
mice from 51 peer-reviewed scientific papers [19, 32-82] were included in the analysis. Table 1 illustrates the included peer-reviewed study and mouse sample sizes, as well as study citation references, for each aggregated data pool. Additional details on the data sources can be found in Supplementary Table 1. Unless specified otherwise, stated "n" within the Results text and figure captions is the included mice sample size.

\section{Cognition versus amyloid- $\beta$ levels}

Correlation of the relationship between total $A \beta$ plaque levels and day five MWM escape latency was measured by meta-data analysis (Fig. 1A). Data points represent the aggregated average of a group of mice from a single experiment, where the line of best fit is weighted based on sample size for each aggregate point. Data point weighting and hippocampal protein measurements was consistent across all correlation analysis within our study. As expected from large experimental variance in data across the field [15], the Grubb outlier test identified 9 definitive aggregate data points as outliers, which were ultimately removed to insure integrity of the analysis. We plotted the experimentally treated mouse escape latency normalized to a $3 \mathrm{xTg}-\mathrm{AD}$ control mouse versus the normalized total $A \beta$ levels (Fig. 1A). Total $A \beta$ had a statistically significant correlation to MWM escape latency, but it was a rather weak trend (slope $=0.336, \mathrm{R}^{2}=0.149, n=259, p<0.001$ ). To support results in the MWM, an equivalent test and set up was run for NOR (Fig. 1B). NOR recognition index scores supported the results in MWM, revealing a statistically significant but very weak trend with cognition (slope $=-0.156, \mathrm{R}^{2}=0.064, n=116$, $p<0.05$ ).

To compare levels of each $A \beta$ form (soluble $A \beta_{42}$, soluble $A \beta_{40}$, insoluble $A \beta_{42}$, and insoluble $A \beta_{40}$ ), individual analysis on the relationship between cognitive function and levels of each $A \beta$ was completed. Percent control escape latency in the MWM at day five was plotted against each individual percent control in $\mathrm{A} \beta$ (Fig. 2). Both soluble $A \beta$ forms showed weak, but nonetheless statistically significant trends with cognitive function (slope $=0.148, \mathrm{R}^{2}=0.247, p<0.001, n=148$; slope $=0.135, \mathrm{R}^{2}=0.1667, p<0.001, n=148$, for $A \beta_{40}$ and $A \beta_{42}$, respectively) (Fig. $2 A, C$ ). Insoluble $A \beta_{40}$ and $A \beta_{42}$ showed no statistically significant correlation with MWM escape latency (Fig. 2B, D). The nearly flat trendlines with very low $\mathrm{R}^{2}$ values indicate that insoluble $A \beta$ levels did not correlate with cognitive function (slopes $<0.005, \mathrm{R}^{2}<0.001$, $p>>0.05, n=144)$.

$\mathrm{A} \beta$ data measurements fell into two main categories: direct measurement (staining and imaging of plaques or western blot with total $A \beta$ marker like $6 \mathrm{E} 10)$ and indirect calculations (combination of soluble and insoluble $A \beta_{40}$ and $A \beta_{42}$ measurements). When assessed separately, the direct measurements of $\mathrm{A} \beta$ have a stronger correlation with cognition, which is statistically significant (slope $=0.901, \mathrm{R}^{2}=0.464$, $n=93, p<<0.001$ ) (Fig. 2E).

Overall, our assessment of the 3xTg-AD mouse model supports previous results shown in the Tg2576 mouse model [15], which indicate that $A \beta$ and its subforms only weakly correlate with cognitive function. Moreover, the weak trend with cognition is predominantly tied to soluble $A \beta$ that has been directly experimentally measured.

\section{Cognition versus total tau levels}

Both total tau and pTau were analyzed for their contributions to the 3xTg-AD pathology. Total tau (unphosphorylated + phosphorylated tau) showed no trend in either MWM or NOR (Fig. 3). Total tau, also referred to as simply "tau" in the present study, is measured by anti-human tau antibody HT7 or Tau-5, which bind to a location on tau that allows recognition of both unphosphorylated and phosphorylated tau [83, 84]. The trend slopes of the present study indicate increases in total tau mildly improve cognitive function in the $3 \times \mathrm{Tg}$-AD mouse. Of note is that most data were centralized around $100 \%$ of control for total tau indicating total tau levels in treated mice did not change much compared to the control. Pearson coefficient analysis for MWM escape latency versus total tau produced a statistically significant but very weak trend (slope $=-0.176$, $\left.\mathrm{R}^{2}=0.071, p<0.001, n=152\right)$. NOR performance had a nearly flat trendline (slope $=0.0467, \mathrm{R}^{2}=0.006$, $p>>0.05, n=85$ ) with most total tau data once again clustered at $100 \%$ of control.

\section{Cognition versus phosphorylated tau levels}

Although analysis of total tau showed no association with cognitive decline, pTau has a statistically significant and strong association with cognitive decline (Fig. 4). A significant positive slope with MWM escape latency (Fig. 4A) illustrates that cognitive function significantly decreases as pTau 
levels increase (slope $=0.408, \mathrm{R}^{2}=0.275, n=371$, $p<<0.01$ ). Similarly, a significant negative slope with NOR (Fig. 4B) indicates cognitive function decreases as pTau levels increase (slope $=-0.3196$, $\left.\mathrm{R}^{2}=0.176, n=113, p<0.05\right)$. Recall that standard field definitions denote the performance sign for cognitive decline oppositely in MWM and NOR; thus, increased MWM escape latency (positive slope) and decreased NOR recognition index (negative slope) both correspond to increases in cognitive decline. Therefore, the visualized slopes and calculated statistically significant $p$-values indicate a consistent and definitive correlation of pTau with $3 \times$ Tg-AD mouse cognitive decline.

pTau was measured through western blot, imaging of the hippocampus, or ELISA. In all cases, expression units were presented as relative to a $3 \times \mathrm{Tg}-\mathrm{AD}$ control. Imaging of immunohistologically marked pTau provides direct measurement of NFTs. The other measurements also indicate hyperphosphorylation and accumulation of NFTs.

pTau correlation with MWM escape latency surpassed $A \beta$ with a steeper slope of 0.408 and $\mathrm{R}^{2}=0.275$. To confirm the comparison between $\mathrm{pTau}$ and $A \beta$, the proteins were used as variables to predict escape latency performance in a multiple linear regression. Using the MATLAB stepwise function on data points where both $p$ Tau and $A \beta$ were available, it was determined that pTau was a stronger variable input for predicting cognitive function than $\mathrm{A} \beta$. Both variables considered alone were significant factors for improving correlation, but adding the $A \beta$ variable to the pTau trendline did not significantly improve the resulting correlation (data not shown).

pTau epitopes are expressed inconsistently between studies as well as within the same study. There is not a definitive epitope that is considered the most impactful or completely irrelevant. AT8, AT270, AT180, and PHF-1 monoclonal antibody markers were compared to determine if one had a more consistent measurement and correlation with MWM performance (Fig. 5). The major kinases involved in pTau pathology contribute to phosphorylation at multiple sites including all the sites detected by AT8, AT180, AT270, and PHF-1 (Table 2). Additionally, the major phosphorylation sites of pGSK3 $\beta$ and CDK5 are captured by these antibodies. Both AT8 and AT270 were significant and had relatively strong, positive correlations. PHF-1 and AT180 had no significant trends with escape latency, and they even have slightly negative slopes.

\section{Assessment of variance and disease complexity}

A PCA calculated contribution of individual components to variance in the data and provided an overall assessment of disease complexity. In addition to the clinical outcome measures discussed so far, kinases and kinase activators involved in tau phosphorylation (pGSK3 $\beta$, GSK3 $\beta$, CDK5, p25, and p35) were analyzed to identify possible targets for future research (Fig. 6, Table 2). PCA calculates components that explain the largest amount of variance, whereas a biplot displays how much variables contribute to variance for the predominant two PCA-identified components. Six outlier data points, which were included in the full PCA analysis in Fig. 6A-C (analysis including outliers) were removed for the PCA analysis illustrated in Fig. 6D-F (analysis excluding outliers). Note that the important considerations for comparison are the orthogonality of the variables and overall contribution to variance explained. Correlating variables cluster together on the biplot(s) (Fig. 6A,D) and contribute similarly to variance of the pathological "system".

In both PCA analyses (including and excluding outliers), phosphorylated (ser 9) GSK3 $\beta$ (pGSK3 $\beta$ ) contributed most strongly to variance in the "system", and pTau and MWM escape latency contribute to variance in a nearly collinear manner. In the analysis excluding outliers (Fig. 6D-F), Component 1 of PCA accounted for $86.6 \%$ of the variance and was mostly comprised of pGSK3 $\beta$ (Fig. 6E) while component 2 accounted for $14.4 \%$ of the variance and was dominated by pTau (Fig. 6F). In the analysis including outliers (Fig. 6A-C), component 1 of PCA accounted for $63.6 \%$ of the variance and was mostly comprised of pGSK3 $\beta$ (Fig. 6B) while component 2 accounted for $26.9 \%$ of the variance and was dominated by p25 (Fig. 6C), which is a crucial activator of CDK5.

\section{DISCUSSION}

Total levels of directly measured $A \beta$, as well as pTau both correlated with cognitive decline in the MWM and NOR. However, pTau had a stronger and more definitive trendline, indicating that despite its lower overall concentration, pTau has a stronger connection to cognitive ability in $3 \times \mathrm{Tg}-\mathrm{AD}$ transgenic mice than does $A \beta$ [85]. Individual $A \beta$ subform analysis supports previous findings that $A \beta$ correlates weakly with cognitive decline and has a limited effect on cognitive changes [15]. Inconsistent trends 
(A)

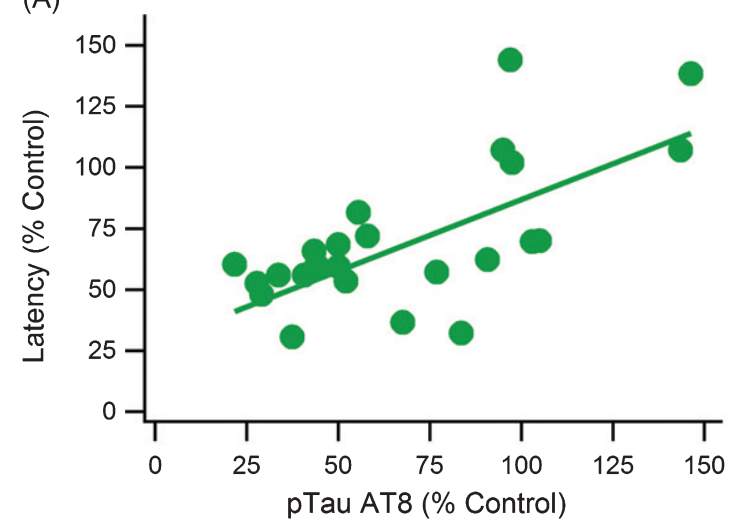

(C)

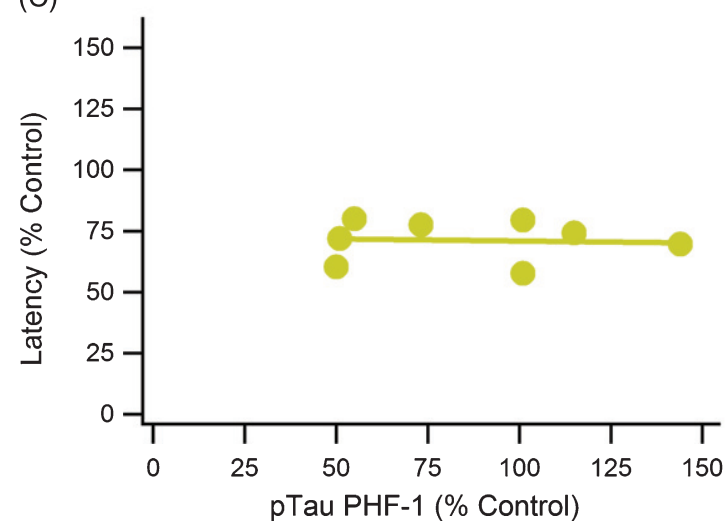

(B)

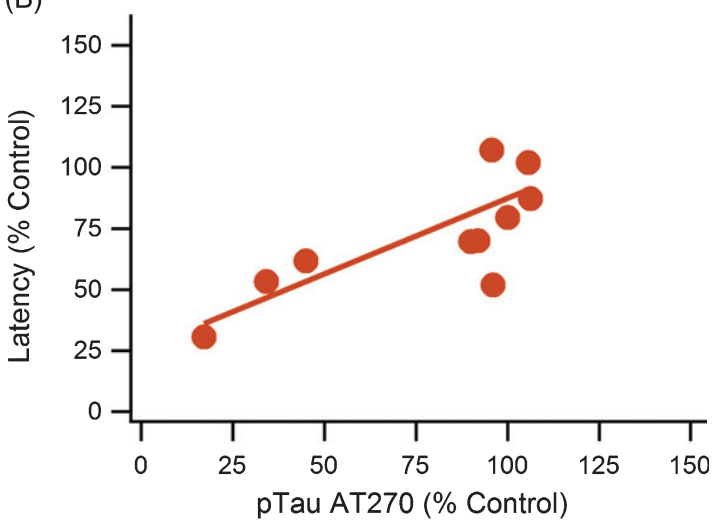

(D)

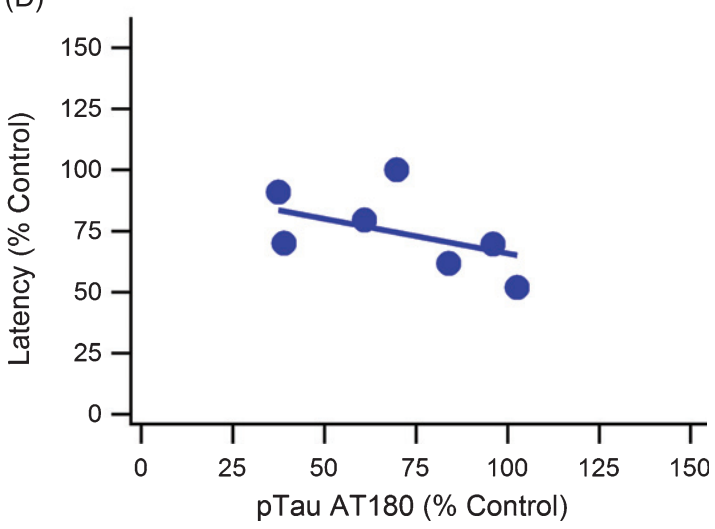

Fig. 5. pTau epitope analysis comparing different phosphorylation locations. pTau epitope breakdown shows strong positive correlations with AT8 and AT270 while showing no trend or a weak, negative trend with PHF-1 and AT180, respectively. A) AT8: slope $=0.586, \mathrm{R}^{2}=0.521$, $n=185, p<<0.001$. B) AT270: slope $=0.619, \mathrm{R}^{2}=0.686, n=88, p<<0.001$. C) PHF-1: slope $=-0.017, \mathrm{R}^{2}=0.004, n=48, p>>0.05$. D) AT180: slope $=-0.285, \mathrm{R}^{2}=0.242, n=44, p<0.001$. Note that sample sizes noticeably decreased from A to D due to a lack of data and measurements using the AT180 and PHF-1 markers.

Table 2

Phosphorylated tau antibody reference guide for phosphorylation location

\begin{tabular}{|c|c|c|c|}
\hline Antibody Epitope & Phosphorylation Site(s) & Kinases Involved & References \\
\hline$\overline{\text { AT8 }}$ & $\mathrm{Ser}^{199}, \mathrm{Ser}^{202}$, and $\mathrm{Thr}^{205}$ & $\begin{array}{l}\text { pGSK3 } \beta, \text { GSK3 } \beta, \text { CDK5, } \\
\text { MAPKs (JNK, ERK2), p38 }\end{array}$ & {$[23,104-107]$} \\
\hline AT180 & $\mathrm{Thr}^{231}$ and $\mathrm{Ser}^{235}$ & $\begin{array}{l}\text { pGSK } 3 \beta, \text { GSK3 } 3, \text { CDK5, } \\
\text { MAPKs (JNK, ERK2), p38 }\end{array}$ & [104-107] \\
\hline AT270 & $\operatorname{Thr}^{181}$ & $\begin{array}{l}\text { pGSK } 3 \beta, \text { GSK } 3 \beta, \text { CDK5, } \\
\text { MAPKs (JNK, ERK2), p38 }\end{array}$ & [104-106] \\
\hline PHF-1 & $\operatorname{Ser}^{396}$ and $\operatorname{Ser}^{404}$ & $\begin{array}{l}\text { pGSK } 3 \beta, \text { GSK3 } \beta, \text { CDK5, } \\
\text { MAPKs (JNK, ERK2), p38 }\end{array}$ & [104-107] \\
\hline
\end{tabular}

amongst the pTau antibodies presents an interesting discussion on the quality of pTau epitope markers and phosphorylation location influence on self-assembly into NFTs. PCA emphasized the need for further investigation of tau phosphorylation mechanisms and the intricate complexity of AD pathology, which suggests the need for combinatorial therapeutic strategies to target synergy between $A \beta$ and pTau in NFT formation, possibly via $\mathrm{PGSK} 3 \beta$.

\section{Relative comparison of wild type affirms} $3 x T g-A D$ model validity

Relative pTau and $A \beta$ protein levels of wild type mice to $3 x T g-A D$ control mice coincided with relative escape latencies of treated $3 \times \mathrm{Tg}-\mathrm{AD}$ mice with a similar reduction in pTau and $\mathrm{A} \beta$. A $50 \%$ level of pTau compared to an untreated 3xTg-AD control led to a 30-50\% reduction in escape latency for both 
(A)

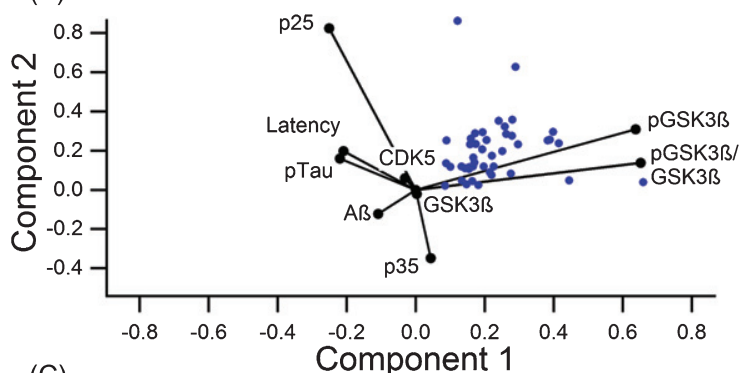

(C)
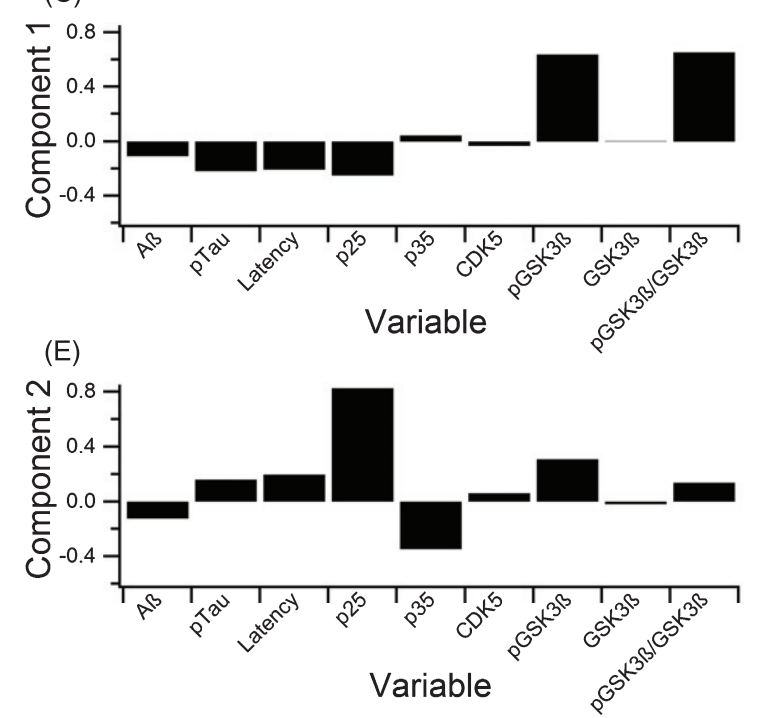

(B)

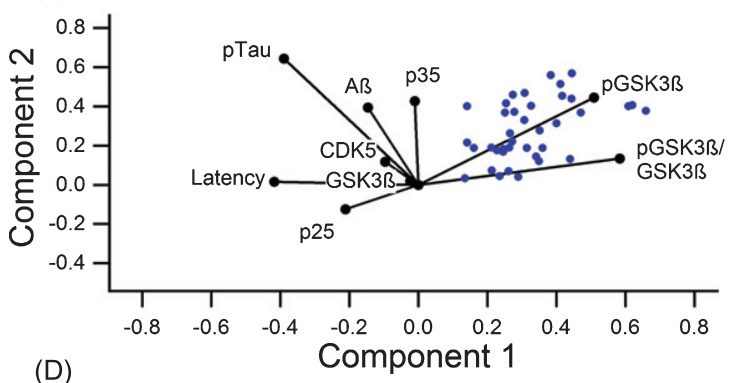

(D)

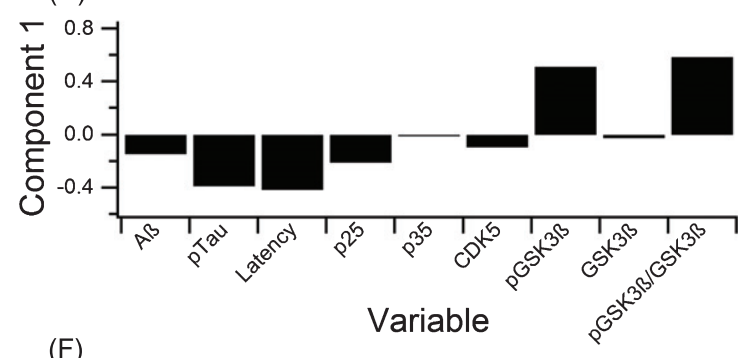

(F)

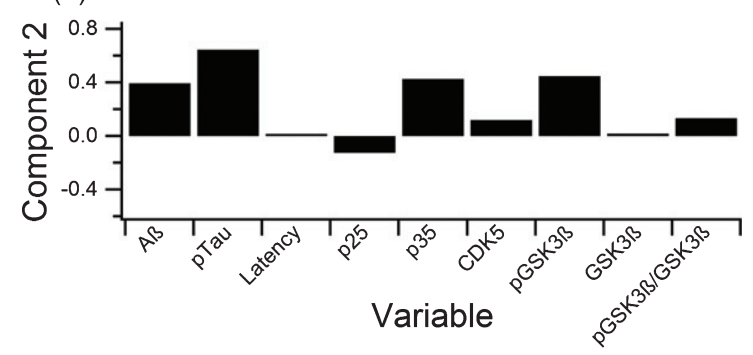

Fig. 6. PCA to determine variance contribution of the key components in tau phosphorylation. A-C) PCA on all data with no outlier removal graphed in the biplot (A) and broken down to clearly show the first two components (B, C). Component 1 accounted for $63.6 \%$ of the variance, and component 2 accounted for $27.9 \%$. D-F) PCA on data with six outliers removed displayed in a biplot (A) and broken down to show the first two components (E, F). Component 1 accounted for $86.6 \%$ of the variance, and component 2 accounted for $13.4 \%$.

treated $3 \times \mathrm{Tg}-\mathrm{AD}$ and untreated wild type mice. The alignment of wild type data supports the validity and consistency of using 3xTg-AD control mice. Moreover, wild type mice provide the lower limit on how fast the mice can swim and find the platform with no AD pathology [27].

\section{Amyloid- $\beta$ displays weak trends with cognitive decline}

Increases in total $\mathrm{A} \beta$ showed only weak trends with cognitive decline, which was supported by the individual analysis of the four main forms of the $A \beta$ components. As similarly shown in prior work in meta-analysis of other preclinical AD mouse models [15], the trends with insoluble $A \beta$ were insignificant, and thus were not an indication of cognitive decline. Despite insoluble A $\beta$ typically having higher concentrations in the brain, relative changes in the soluble $A \beta$ levels had a larger impact on cognitive function $[39,60,78]$. The diffuse nature of soluble $\mathrm{A} \beta$ allows it to have a more direct impact on neurons by surrounding the cell surface and synapses leading to neurotoxicity [86-88]. The connection between $A \beta$ and tau phosphorylation is not well defined, but significant trends could indicate soluble $\mathrm{A} \beta$ oligomers have a stronger influence in activating kinases for tau phosphorylation [89]. In contrast to other $A \beta$ assessments, direct $A \beta$ experimental measurements moderately correlated with escape latency $\left(R^{2}=0.464\right)$ (Fig. 2E), but pTau correlated even more strongly with escape latency for studies where both $\mathrm{A} \beta$ and pTau measurements were available ( 9 out of 12 studies; $\mathrm{R}^{2}=0.847$ ). The present analysis supports the indirect role that $A \beta$ plays in the Amyloid Cascade Hypothesis, but the variance and weak overall trendlines of $A \beta$ with cognition reinforce the complexity of the interaction. Thus, while $A \beta$ may be the 
most physically visible marker of $\mathrm{AD}$, its actual role in the disease etiology, and namely, cognitive decline, is neither independent nor direct, but rather, intertwined with mechanisms like pTau and GSK-3 $\beta$. For these reasons, $A \beta$ is likely not the best primary treatment target - a conclusion supported by the mounds of failed clinical trials specifically targeting $A \beta$ in $\mathrm{AD}[13,14]$.

\section{Total tau is insignificant to cognitive decline}

Total tau, often referred to simply as "tau", did not have a clear impact on cognitive decline, and qualitative trends even indicated that it may improve cognitive ability. The aforementioned result is rather unsurprising considering tau is a normal and prevalent protein in the brain that is needed for microtubule stabilization and proper neuron function [90, 91]. Additionally, even when overexpressed, tau does not aggregate into NFTs because of its naturally high solubility [92]. Moreover, tau trends were not definitive in large part because the tau in treated mice did not differ from the control mice substantially in many of the experiments; the measurements tended to be within $10-20 \%$ of the control value. Such a sensitive range may not allow meaningful assessment of cognitive impact with MWM and/or NOR, especially in a complex disease with numerous other contributing factors.

\section{Phosphorylated tau levels strongly correlate with cognitive decline}

pTau showed statistically significant and very strong quantitative trends with cognitive performance in both the MWM and NOR cognitive tests. The overall impact of tau phosphorylation by kinases had similar impact in the MWM and NOR tests, reinforcing results of the impact of pTau on the hippocampus and cognitive function. Individual breakdown of pTau epitopes (AT8, AT180, AT270, and PHF-1) revealed there were differences in predicting cognitive function. AT8 and AT270 had a strong correlation between increasing levels and cognitive decline; however, AT8 had more supporting data promoting a strong correlation between increased pTau levels and increased latency in the MWM. Therefore, AT8 could be the most effective and consistent method in measuring pTau level. Both PHF-1 and AT180 resulted in very low correlation between escape latency and pTau levels, but their trends were likely distorted by insufficient sample size. Further research on tau epitope binding characteristics is needed to understand accuracy of measurement, impact on variance, and standard experimental error. The presented results of our aggregated analysis beg the question, "Is there a lack of consistency between the experimental antibodies, or does phosphorylation location impact the ability to self-assemble into NFTs?"

\section{Phosphorylated tau more directly influences cognitive decline than $A \beta$}

The overall impact of pTau in 3xTg-AD cognitive decline is consistent and clear: p-Tau has a statistically significant and strong correlation with cognitive function that outweighs that of $A \beta$ as shown in multiple forms of analysis in the present study, including side-by-side analytical comparisons of aggregated data from studies examining both $\mathrm{A} \beta$ and $\mathrm{pTau}$ versus cognition, aggregated analysis of studies separately assessing $A \beta$ and $p$ Tau versus cognition, multiple linear regression assessing the ability of $A \beta$ and/or pTau to predict cognitive decline, and PCA examining contributors to variance in MWM escape latency.

pTau's greater impact on cognition than $A \beta$ is all the more impressive considering pTau deposits are not as substantial, in terms of visual surface area prevalence and concentration in cerebrospinal fluid in the brain $[85,93]$. The present study's results suggest that pTau is most likely the primary factor in cognitive decline, though $A \beta$ may play an indirect role in AD pathology in the development of NFTs. Based on the $3 \times$ Tg-AD mouse model, $A \beta$ is the first pathology to develop in $\mathrm{AD}$, suggesting that it may serve as the first link in the chain leading to neurodegeneration by influencing tau phosphorylation; as such, its maximal treatment efficacy is likely limited to very early stages of disease well before onset of cognitive decline. Our conclusions affirm findings of previous studies, including Foley et al. [15], lending further support that while $A \beta$ may contribute to cognitive decline when highly concentrated, quantitative levels of $A \beta$ do not correlate with cognitive decline. In contrast, levels of pTau do significantly, directly, and quantitatively correlate with cognitive decline; therefore, pTau could be a key functional treatment target even in later stages of the AD pathology. The connection between $p$ Tau and $A \beta$ requires further research to precisely and mechanistically define. It is likely, however, that $A \beta$ indirectly promotes tau phosphorylation through upregulation of kinases such as GSK-3 $\beta$ and CDK5, which phosphorylate tau. 


\section{Complexity analysis highlights GSK3} interactions

Glycogen synthase kinase-3 (GSK-3) and CDK5 are kinases involved in the phosphorylation of tau as an important step in AD pathology [4, 94-96]. Our analysis focused around GSK-3 due to its dominance as a tau phosphorylation kinase and prevalence in literature; specifically, the GSK-3 $\beta$ isoform is linked more closely with tau pathology [94]. Additional kinases (PKA, p38 MAPKs, CAMKII, Dyrk1A) were considered, but there was a lack of available data with corresponding $p$ Tau and $A \beta$ measurements for substantial meta-analysis [97]. In both analyses, pGSK $3 \beta$ contributes substantially to variance, which highlights it as prime future research targets to assess mechanisms directly related to escape latency. The large variance in the activator proteins p25 and p35 highlights the need to account for CDK5 involvement in AD. While CDK5 may have had small comparative variance, CDK5 is linked to regulation of $A \beta$ development and pGSK3 $\beta$ activity [95-97]. Therefore, even small changes in activity could be having large downstream effects more directly attributable to $\mathrm{pGSK} 3 \beta$, pTau, and A $\beta$.

In both PCA analyses, the MWM escape latency variance is low in both components; this finding is somewhat expected because there is an inherent limit to the variance in escape latency. pTau and latency closely align in the PCA analysis with outliers and very closely in PCA component 1 in the analysis with outliers removed (Fig. 6E). These findings suggest the presence of collinearity and provide corresponding additional support that pTau more directly influences cognitive decline than $A \beta$ in the $3 x T g-A D$ pathology. Finally, the lack of one predominant factor contributing to overall variance underlines the vast complexity and degree of interactions involved in $\mathrm{AD}$. Thus, $\mathrm{AD}$ will likely require a multi-faceted or combination treatment strategy to achieve clinically meaningful efficacy.

\section{Alzheimer's disease overlap with other neurological diseases}

The complexity that AD shares with other multifactorial neurological diseases does suggest the existence of a spectrum of disorders (i.e., Alzheimer's disease, amyotrophic lateral sclerosis (ALS), Pick's disease, Parkinson's disease, frontotemporal lobar degeneration, etc.) that lay within a continuum, as evidenced by clinical biomarker overlap identified in ALS clinical patient autopsies [98]. In fact, more than $20 \%$ of sporadic ALS patients in a recent biomarker autopsy study [98] met CERAD (Consortium for Established Registry for Alzheimer's Disease) criteria for $\mathrm{AD}$; moreover, over $35 \%$ had excessive $\mathrm{A} \beta, 78 \%$ had NFTs, $17 \%$ had clinical tauopathy, $80 \%$ had TDP-43, and $4 \% \alpha$-synuclein. This example of overlap within ALS illustrates shared etiology across various neuropathologies, irrespective of whether the specific pathology is accompanied by clinically measurable cognitive decline in every patient. Such an intricate neuropathological continuum requires addressing overlapping pathology dynamics $[99,100]$ and targeting synergistic interactions in order to return to neural system homeostasis $[101,102]$. Additional informatics [102] and computational assessments (e.g., [21, 99, 100, 101, 103]) to further explore underlying complexity, system dynamics, and system stability could expedite combination treatment identification.

\section{Conclusions and future directions}

The present systematic review, which compares $\mathrm{A} \beta$ and tau pathology in the $3 \mathrm{xTg}-\mathrm{AD}$ mouse model, concludes that pTau has the strongest correlation to cognitive decline than any of the other assessed clinical outcome measures, including $A \beta$. Thus, particularly in sporadic or non-familial cases of clinical $\mathrm{AD}, \mathrm{A} \beta$ should not be the sole therapeutic target to improve AD symptoms. Future research should focus on eliminating pTau to reverse AD symptoms, rather than focusing solely on $A \beta$ elimination (Fig. 7). Preventing $A \beta$ accumulation, even before

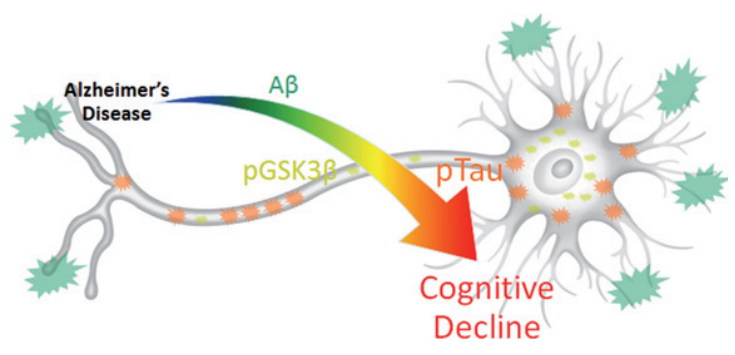

Fig. 7. Results summary figure highlighting the physical levels of biomarkers and their corresponding correlation intensity with cognitive decline. pTau is most directly and quantitatively linked to cognitive decline despite its overall lower physical concentration and lower visual presence compared to A $\beta$. pGSK $3 \beta$, which contributes the most to data variance in 3xTg-AD MWM escape latency, may provide the key to harnessing synergistic complex interactions between $A \beta$ and pTau that result in cognitive decline. 
onset, can reduce NFT build up and reduce the corresponding protein accumulations in the brain, but such prophylactic treatment is only well-suited in cases of known familial lineage or history, where treatment can begin well before the onset of cognitive decline [10]. Alternative options for sporadic AD could include protein regulator treatments to moderate the activity of kinases like pGSK3 $\beta$ to prevent hyperphosphorylation of tau, which would allow normal pGSK3 $\beta$ function without complete elimination. The large variance in all aspects of the trendlines and in the PCA suggest that many additional factors are affecting the AD pathology and the overall outcome of cognitive ability. Due to the complex interactions between multiple proteins in a disease with distinctive emergent properties, a multifaceted and synergistic treatment approach is needed that aligns with the temporal and functional $\mathrm{AD}$ disease stages and corresponding pathology dynamics. We conclude that a larger research focus on higher-level interactions among key proteins, including $A \beta$, GSK- $3 \beta$, and pTau, will give a better understanding of the complex dynamics that must be addressed for the development of effective clinical remedies.

\section{ACKNOWLEDGMENTS}

Funding provided by the National Institute of Health Grants NS069616, NS098228, and NS081426 to CSM.

Authors' disclosures available online (http://j-alz. com/manuscript-disclosures/17-0490r2).

\section{SUPPLEMENTARY MATERIAL}

The supplementary material is available in the electronic version of this article: http://dx.doi.org/ 10.3233/JAD-170490.

\section{REFERENCES}

[1] Lopez-Gonzalez I, Schluter A, Aso E, Garcia-Esparcia P, Ansoleaga B, F LL, Carmona M, Moreno J, Fuso A, Portero-Otin M, Pamplona R, Pujol A, Ferrer I (2015) Neuroinflammatory signals in Alzheimer disease and APP/PS1 transgenic mice: Correlations with plaques, tangles, and oligomeric species. J Neuropathol Exp Neurol 74, 319-344.

[2] Serrano-Pozo A, Frosch MP, Masliah E, Hyman BT (2011) Neuropathological alterations in Alzheimer disease. Cold Spring Harb Perspect Med 1, a006189.

[3] Hernandez F, Gomez de Barreda E, Fuster-Matanzo A, Lucas JJ, Avila J (2010) GSK3: A possible link between beta amyloid peptide and tau protein. Exp Neurol 223, 322-325.

[4] Hooper C, Killick R, Lovestone S (2008) The GSK3 hypothesis of Alzheimer's disease. J Neurochem 104, 1433-1439.

[5] Spires-Jones TL, Hyman BT (2014) The intersection of amyloid beta and tau at synapses in Alzheimer's disease. Neuron 82, 756-771.

[6] DaRocha-Souto B, Scotton TC, Coma M, Serrano-Pozo A, Hashimoto T, Sereno L, Rodriguez M, Sanchez B, Hyman BT, Gomez-Isla T (2011) Brain oligomeric beta-amyloid but not total amyloid plaque burden correlates with neuronal loss and astrocyte inflammatory response in amyloid precursor protein/tau transgenic mice. J Neuropathol Exp Neurol 70, 360-376.

[7] Sakono M, Zako T (2010) Amyloid oligomers: Formation and toxicity of Abeta oligomers. FEBS J 277, 1348-1358.

[8] Sengupta U, Nilson AN, Kayed R (2016) The role of amyloid-beta oligomers in toxicity, propagation, and immunotherapy. EBioMedicine 6, 42-49.

[9] Oddo S, Billings L, Kesslak JP, Cribbs DH, LaFerla FM (2004) Abeta immunotherapy leads to clearance of early, but not late, hyperphosphorylated tau aggregates via the proteasome. Neuron 43, 321-332.

[10] Iaccarino HF, Singer AC, Martorell AJ, Rudenko A, Gao F, Gillingham TZ, Mathys H, Seo J, Kritskiy O, Abdurrob F, Adaikkan C, Canter RG, Rueda R, Brown EN, Boyden ES, Tsai LH (2016) Gamma frequency entrainment attenuates amyloid load and modifies microglia. Nature 540, 230-235.

[11] Castillo-Carranza DL, Guerrero-Munoz MJ, Sengupta U, Hernandez C, Barrett AD, Dineley K, Kayed R (2015) Tau immunotherapy modulates both pathological tau and upstream amyloid pathology in an Alzheimer's disease mouse model. J Neurosci 35, 4857-4868.

[12] Hardy JA, Higgins GA (1992) Alzheimer's disease: The amyloid cascade hypothesis. Science 256, 184-185.

[13] Briggs R, Kennelly SP, O’Neill D (2016) Drug treatments in Alzheimer's disease. Clin Med (Lond) 16, 247-253.

[14] Galimberti D, Scarpini E (2016) Old and new acetylcholinesterase inhibitors for Alzheimer's disease. Expert Opin Investig Drugs 25, 1181-1187.

[15] Foley AM, Ammar ZM, Lee RH, Mitchell CS (2015) Systematic review of the relationship between amyloidbeta levels and measures of transgenic mouse cognitive deficit in Alzheimer's disease. J Alzheimers Dis 44, 787-795.

[16] Oddo S, Caccamo A, Shepherd JD, Murphy MP, Golde TE, Kayed R, Metherate R, Mattson MP, Akbari Y, LaFerla FM (2003) Triple-transgenic model of Alzheimer's disease with plaques and tangles: Intracellular Abeta and synaptic dysfunction. Neuron 39, 409-421.

[17] Barten DM, Cadelina GW, Hoque N, DeCarr LB, Guss VL, Yang L, Sankaranarayanan S, Wes PD, Flynn ME, Meredith JE, Ahlijanian MK, Albright CF (2011) Tau transgenic mice as models for cerebrospinal fluid tau biomarkers. J Alzheimers Dis 24(Suppl 2), 127-141.

[18] Oddo S, Caccamo A, Kitazawa M, Tseng BP, LaFerla FM (2003) Amyloid deposition precedes tangle formation in a triple transgenic model of Alzheimer's disease. Neurobiol Aging 24, 1063-1070.

[19] Green KN, Steffan JS, Martinez-Coria H, Sun X, Schreiber SS, Thompson LM, LaFerla FM (2008) Nicotinamide restores cognition in Alzheimer's disease transgenic mice via a mechanism involving sirtuin inhibition and selec- 
tive reduction of Thr231-phosphotau. J Neurosci 28, 11500-11510.

[20] D'Hooge R, De Deyn PP (2001) Applications of the Morris water maze in the study of learning and memory. Brain Res Brain Res Rev 36, 60-90.

[21] Mitchell CS, Cates A, Kim RB, Hollinger SK (2015) Undergraduate biocuration: Developing tomorrow's researchers while mining today's data. J Undergrad Neurosci Educ 14, A56-A65.

[22] Mastrangelo MA, Bowers WJ (2008) Detailed immunohistochemical characterization of temporal and spatial progression of Alzheimer's disease-related pathologies in male triple-transgenic mice. BMC Neurosci $\mathbf{9}, 81$.

[23] Billings LM, Oddo S, Green KN, McGaugh JL, LaFerla FM (2005) Intraneuronal Abeta causes the onset of early Alzheimer's disease-related cognitive deficits in transgenic mice. Neuron 45, 675-688.

[24] Morris R (1984) Developments of a water-maze procedure for studying spatial learning in the rat. J Neurosci Methods 11, 47-60.

[25] Vorhees CV, Williams MT (2006) Morris water maze: Procedures for assessing spatial and related forms of learning and memory. Nat Protoc 1, 848-858.

[26] Weitzner DS, Engler-Chiurazzi EB, Kotilinek LA, Ashe KH, Reed MN (2015) Morris water maze test: Optimization for mouse strain and testing environment. $J$ Vis Exp, e52706.

[27] Morris RG, Schenk F, Tweedie F, Jarrard LE (1990) Ibotenate lesions of hippocampus and/or subiculum: Dissociating components of allocentric spatial learning. Eur J Neurosci 2, 1016-1028.

[28] Sharma S, Rakoczy S, Brown-Borg H (2010) Assessment of spatial memory in mice. Life Sci 87, 521-536.

[29] Anderson EM, Moenk MD, Barbaro L, Clarke DA, Matuszewich L (2013) Effects of pretraining and water temperature on female rats' performance in the Morris water maze. Physiol Behav 122, 216-221.

[30] Antunes M, Biala G (2012) The novel object recognition memory: Neurobiology, test procedure, and its modifications. Cogn Process 13, 93-110.

[31] Block F (1999) Global ischemia and behavioural deficits. Prog Neurobiol 58, 279-295.

[32] Medeiros R, Kitazawa M, Caccamo A, Baglietto-Vargas D, Estrada-Hernandez T, Cribbs DH, Fisher A, LaFerla FM (2011) Loss of muscarinic M1 receptor exacerbates Alzheimer's disease-like pathology and cognitive decline. Am J Pathol 179, 980-991.

[33] Ager RR, Davis JL, Agazaryan A, Benavente F, Poon WW, LaFerla FM, Blurton-Jones M (2015) Human neural stem cells improve cognition and promote synaptic growth in two complementary transgenic models of Alzheimer's disease and neuronal loss. Hippocampus 25, 813-826.

[34] Baglietto-Vargas D, Chen Y, Suh D, Ager RR, RodriguezOrtiz CJ, Medeiros R, Myczek K, Green KN, Baram TZ, LaFerla FM (2015) Short-term modern life-like stress exacerbates Abeta-pathology and synapse loss in 3xTgAD mice. J Neurochem 134, 915-926.

[35] Baglietto-Vargas D, Kitazawa M, Le EJ, EstradaHernandez T, Rodriguez-Ortiz CJ, Medeiros R, Green KN, LaFerla FM (2014) Endogenous murine tau promotes neurofibrillary tangles in $3 \mathrm{xTg}-\mathrm{AD}$ mice without affecting cognition. Neurobiol Dis 62, 407-415.

[36] Baglietto-Vargas D, Medeiros R, Martinez-Coria H, LaFerla FM, Green KN (2013) Mifepristone alters amy- loid precursor protein processing to preclude amyloid beta and also reduces tau pathology. Biol Psychiatry 74, 357-366.

[37] Barron AM, Rosario ER, Elteriefi R, Pike CJ (2013) Sexspecific effects of high fat diet on indices of metabolic syndrome in 3xTg-AD mice: Implications for Alzheimer's disease. PLoS One 8, e78554.

[38] Blanchard J, Wanka L, Tung YC, Cardenas-Aguayo Mdel C, LaFerla FM, Iqbal K, Grundke-Iqbal I (2010) Pharmacologic reversal of neurogenic and neuroplastic abnormalities and cognitive impairments without affecting Abeta and tau pathologies in 3xTg-AD mice. Acta Neuropathol 120, 605-621.

[39] Blurton-Jones M, Kitazawa M, Martinez-Coria H, Castello NA, Muller FJ, Loring JF, Yamasaki TR, Poon WW, Green KN, LaFerla FM (2009) Neural stem cells improve cognition via BDNF in a transgenic model of Alzheimer disease. Proc Natl Acad Sci U S A 106, 1359413599.

[40] Bomba M, Ciavardelli D, Silvestri E, Canzoniero LM, Lattanzio R, Chiappini P, Piantelli M, Di Ilio C, Consoli A, Sensi SL (2013) Exenatide promotes cognitive enhancement and positive brain metabolic changes in PS1-KI mice but has no effects in 3xTg-AD animals. Cell Death Dis $\mathbf{4}$, e612.

[41] Branca C, Wisely EV, Hartman LK, Caccamo A, Oddo S (2014) Administration of a selective beta2 adrenergic receptor antagonist exacerbates neuropathology and cognitive deficits in a mouse model of Alzheimer's disease. Neurobiol Aging 35, 2726-2735.

[42] Chadwick W, Mitchell N, Caroll J, Zhou Y, Park SS, Wang L, Becker KG, Zhang Y, Lehrmann E, Wood WH, 3rd, Martin B, Maudsley S (2011) Amitriptyline-mediated cognitive enhancement in aged 3xTg Alzheimer's disease mice is associated with neurogenesis and neurotrophic activity. PLoS One 6, e21660.

[43] Chen Y, Liang Z, Tian Z, Blanchard J, Dai CL, Chalbot S, Iqbal K, Liu F, Gong CX (2014) Intracerebroventricular streptozotocin exacerbates Alzheimerlike changes of 3xTg-AD mice. Mol Neurobiol 49, 547-562.

[44] Corona C, Frazzini V, Silvestri E, Lattanzio R, La Sorda R, Piantelli M, Canzoniero LM, Ciavardelli D, Rizzarelli E, Sensi SL (2011) Effects of dietary supplementation of carnosine on mitochondrial dysfunction, amyloid pathology, and cognitive deficits in $3 \mathrm{xTg}-\mathrm{AD}$ mice. PLoS One 6, e17971.

[45] Corona C, Masciopinto F, Silvestri E, Viscovo AD, Lattanzio R, Sorda RL, Ciavardelli D, Goglia F, Piantelli M, Canzoniero LM, Sensi SL (2010) Dietary zinc supplementation of 3xTg-AD mice increases BDNF levels and prevents cognitive deficits as well as mitochondrial dysfunction. Cell Death Dis 1, e91.

[46] Dagher NN, Najafi AR, Kayala KM, Elmore MR, White TE, Medeiros R, West BL, Green KN (2015) Colonystimulating factor 1 receptor inhibition prevents microglial plaque association and improves cognition in $3 \times \mathrm{Tg}-\mathrm{AD}$ mice. J Neuroinflammation 12, 139.

[47] Dai CL, Chen X, Kazim SF, Liu F, Gong CX, GrundkeIqbal I, Iqbal K (2015) Passive immunization targeting the $\mathrm{N}$-terminal projection domain of tau decreases tau pathology and improves cognition in a transgenic mouse model of Alzheimer disease and tauopathies. J Neural Transm (Vienna) 122, 607-617. 
[48] Di Meco A, Joshi YB, Pratico D (2014) Sleep deprivation impairs memory, tau metabolism, and synaptic integrity of a mouse model of Alzheimer's disease with plaques and tangles. Neurobiol Aging 35, 1813-1820.

[49] Fisher A, Bezprozvanny I, Wu L, Ryskamp DA, Bar-Ner N, Natan N, Brandeis R, Elkon H, Nahum V, Gershonov E, LaFerla FM, Medeiros R (2016) AF710B, a novel M1/sigma1 agonist with therapeutic efficacy in animal models of Alzheimer's disease. Neurodegener Dis 16, 95110.

[50] Giuliani D, Bitto A, Galantucci M, Zaffe D, Ottani A, Irrera N, Neri L, Cavallini GM, Altavilla D, Botticelli AR, Squadrito F, Guarini S (2014) Melanocortins protect against progression of Alzheimer's disease in tripletransgenic mice by targeting multiple pathophysiological pathways. Neurobiol Aging 35, 537-547.

[51] Giuliani D, Ottani A, Zaffe D, Galantucci M, Strinati F, Lodi R, Guarini S (2013) Hydrogen sulfide slows down progression of experimental Alzheimer's disease by targeting multiple pathophysiological mechanisms. Neurobiol Learn Mem 104, 82-91.

[52] Green KN, Khashwji H, Estrada T, Laferla FM (2011) ST101 induces a novel $17 \mathrm{kDa}$ APP cleavage that precludes Abeta generation in vivo. Ann Neurol 69, 831-844.

[53] Halagappa VK, Guo Z, Pearson M, Matsuoka Y, Cutler RG, Laferla FM, Mattson MP (2007) Intermittent fasting and caloric restriction ameliorate age-related behavioral deficits in the triple-transgenic mouse model of Alzheimer's disease. Neurobiol Dis 26, 212-220.

[54] Hu Y, Lai J, Wan B, Liu X, Zhang Y, Zhang J, Sun D, Ruan G, Liu E, Liu GP, Chen C, Wang DW (2016) Long-term exposure to ELF-MF ameliorates cognitive deficits and attenuates tau hyperphosphorylation in 3xTg AD mice. Neurotoxicology 53, 290-300.

[55] Kitazawa M, Cheng D, Tsukamoto MR, Koike MA, Wes PD, Vasilevko V, Cribbs DH, LaFerla FM (2011) Blocking IL-1 signaling rescues cognition, attenuates tau pathology, and restores neuronal beta-catenin pathway function in an Alzheimer's disease model. J Immunol 187, 6539-6549.

[56] Knight EM, Martins IV, Gumusgoz S, Allan SM, Lawrence CB (2014) High-fat diet-induced memory impairment in triple-transgenic Alzheimer's disease (3xTgAD) mice is independent of changes in amyloid and tau pathology. Neurobiol Aging 35, 1821-1832.

[57] Majumder S, Richardson A, Strong R, Oddo S (2011) Inducing autophagy by rapamycin before, but not after, the formation of plaques and tangles ameliorates cognitive deficits. PLoS One 6, e25416.

[58] Marlatt MW, Potter MC, Bayer TA, van Praag H, Lucassen PJ (2013) Prolonged running, not fluoxetine treatment, increases neurogenesis, but does not alter neuropathology, in the $3 \times$ Tg mouse model of Alzheimer's disease. Curr Top Behav Neurosci 15, 313-340.

[59] Martin SA, Jameson CH, Allan SM, Lawrence CB (2014) Maternal high-fat diet worsens memory deficits in the triple-transgenic (3xTgAD) mouse model of Alzheimer's disease. PLoS One 9 , e99226.

[60] Martinez-Coria H, Green KN, Billings LM, Kitazawa M, Albrecht M, Rammes G, Parsons CG, Gupta S, Banerjee P, LaFerla FM (2010) Memantine improves cognition and reduces Alzheimer's-like neuropathology in transgenic mice. Am J Pathol 176, 870-880.
[61] Medeiros R, Castello NA, Cheng D, Kitazawa M, Baglietto-Vargas D, Green KN, Esbenshade TA, Bitner RS, Decker MW, LaFerla FM (2014) alpha7 Nicotinic receptor agonist enhances cognition in aged $3 \times \mathrm{Tg}-\mathrm{AD}$ mice with robust plaques and tangles. Am J Pathol 184, 520-529.

[62] Medina DX, Caccamo A, Oddo S (2011) Methylene blue reduces abeta levels and rescues early cognitive deficit by increasing proteasome activity. Brain Pathol 21, 140-149.

[63] Movsesyan N, Ghochikyan A, Mkrtichyan M, Petrushina I, Davtyan H, Olkhanud PB, Head E, Biragyn A, Cribbs DH, Agadjanyan MG (2008) Reducing AD-like pathology in $3 \times \mathrm{Tg}-\mathrm{AD}$ mouse model by DNA epitope vaccine - a novel immunotherapeutic strategy. PLoS One 3, e2124.

[64] Palm R, Chang J, Blair J, Garcia-Mesa Y, Lee HG, Castellani RJ, Smith MA, Zhu X, Casadesus G (2014) Down-regulation of serum gonadotropins but not estrogen replacement improves cognition in aged-ovariectomized 3xTg AD female mice. J Neurochem 130, 115-125.

[65] Parachikova A, Vasilevko V, Cribbs DH, LaFerla FM, Green KN (2010) Reductions in amyloid-beta-derived neuroinflammation, with minocycline, restore cognition but do not significantly affect tau hyperphosphorylation. J Alzheimers Dis 21, 527-542.

[66] Parrella E, Maxim T, Maialetti F, Zhang L, Wan J, Wei M, Cohen P, Fontana L, Longo VD (2013) Protein restriction cycles reduce IGF-1 and phosphorylated Tau, and improve behavioral performance in an Alzheimer's disease mouse model. Aging Cell 12, 257-268.

[67] Peng J, Liang G, Inan S, Wu Z, Joseph DJ, Meng Q, Peng Y, Eckenhoff MF, Wei H (2012) Dantrolene ameliorates cognitive decline and neuropathology in Alzheimer triple transgenic mice. Neurosci Lett 516, 274-279.

[68] Rasool S, Martinez-Coria H, Milton S, Glabe CG (2013) Nonhuman amyloid oligomer epitope reduces Alzheimer's-like neuropathology in 3xTg-AD transgenic mice. Mol Neurobiol 48, 931-940.

[69] Rasool S, Martinez-Coria H, Wu JW, LaFerla F, Glabe CG (2013) Systemic vaccination with anti-oligomeric monoclonal antibodies improves cognitive function by reducing Abeta deposition and tau pathology in $3 \times \mathrm{Tg}-\mathrm{AD}$ mice. J Neurochem 126, 473-482.

[70] Ratia M, Gimenez-Llort L, Camps P, Munoz-Torrero D, Perez B, Clos MV, Badia A (2013) Huprine X and huperzine $\mathrm{A}$ improve cognition and regulate some neurochemical processes related with Alzheimer's disease in triple transgenic mice (3xTg-AD). Neurodegener Dis 11, 129-140.

[71] Revilla S, Ursulet S, Alvarez-Lopez MJ, Castro-Freire M, Perpina U, Garcia-Mesa Y, Bortolozzi A, Gimenez-Llort L, Kaliman P, Cristofol R, Sarkis C, Sanfeliu C (2014) Lenti-GDNF gene therapy protects against Alzheimer's disease-like neuropathology in 3xTg-AD mice and MC65 cells. CNS Neurosci Ther 20, 961-972.

[72] Sabogal-Guaqueta AM, Munoz-Manco JI, RamirezPineda JR, Lamprea-Rodriguez M, Osorio E, CardonaGomez GP (2015) The flavonoid quercetin ameliorates Alzheimer's disease pathology and protects cognitive and emotional function in aged triple transgenic Alzheimer's disease model mice. Neuropharmacology 93, 134-145.

[73] Sabogal-Guaqueta AM, Osorio E, Cardona-Gomez GP (2016) Linalool reverses neuropathological and behavioral impairments in old triple transgenic Alzheimer's mice. Neuropharmacology 102, 111-120. 
[74] Sandoval-Hernandez AG, Buitrago L, Moreno H, Cardona-Gomez GP, Arboleda G (2015) Role of liver X receptor in AD pathophysiology. PLoS One 10, e0145467.

[75] Sandoval-Hernandez AG, Hernandez HG, Restrepo A, Munoz JI, Bayon GF, Fernandez AF, Fraga MF, CardonaGomez GP, Arboleda H, Arboleda GH (2016) Liver X receptor agonist modifies the DNA methylation profile of synapse and neurogenesis-related genes in the triple transgenic mouse model of Alzheimer's disease. J Mol Neurosci 58, 243-253.

[76] Shin MK, Kim HG, Baek SH, Jung WR, Park DI, Park JS, Jo DG, Kim KL (2014) Neuropep-1 ameliorates learning and memory deficits in an Alzheimer's disease mouse model, increases brain-derived neurotrophic factor expression in the brain, and causes reduction of amyloid beta plaques. Neurobiol Aging 35, 990-1001.

[77] Sung YM, Lee T, Yoon H, DiBattista AM, Song JM, Sohn Y, Moffat EI, Turner RS, Jung M, Kim J, Hoe HS (2013) Mercaptoacetamide-based class II HDAC inhibitor lowers Abeta levels and improves learning and memory in a mouse model of Alzheimer's disease. Exp Neurol 239, 192-201.

[78] Sy M, Kitazawa M, Medeiros R, Whitman L, Cheng D, Lane TE, Laferla FM (2011) Inflammation induced by infection potentiates tau pathological features in transgenic mice. Am J Pathol 178, 2811-2822.

[79] Tweedie D, Ferguson RA, Fishman K, Frankola KA, Van Praag H, Holloway HW, Luo W, Li Y, Caracciolo L, Russo I, Barlati S, Ray B, Lahiri DK, Bosetti F, Greig NH, Rosi S (2012) Tumor necrosis factor-alpha synthesis inhibitor 3,6'-dithiothalidomide attenuates markers of inflammation, Alzheimer pathology and behavioral deficits in animal models of neuroinflammation and Alzheimer's disease. J Neuroinflammation 9, 106.

[80] Wu Z, Yang B, Liu C, Liang G, Liu W, Pickup S, Meng Q, Tian Y, Li S, Eckenhoff MF, Wei H (2015) Longterm dantrolene treatment reduced intraneuronal amyloid in aged Alzheimer triple transgenic mice. Alzheimer Dis Assoc Disord 29, 184-191.

[81] Yu Y, Li X, Blanchard J, Li Y, Iqbal K, Liu F, Gong CX (2015) Insulin sensitizers improve learning and attenuate tau hyperphosphorylation and neuroinflammation in 3xTg-AD mice. J Neural Transm (Vienna) 122, 593-606.

[82] Zumkehr J, Rodriguez-Ortiz CJ, Cheng D, Kieu Z, Wai T, Hawkins C, Kilian J, Lim SL, Medeiros R, Kitazawa M (2015) Ceftriaxone ameliorates tau pathology and cognitive decline via restoration of glial glutamate transporter in a mouse model of Alzheimer's disease. Neurobiol Aging 36, 2260-2271.

[83] Zhang Y, Kurup P, Xu J, Carty N, Fernandez SM, Nygaard HB, Pittenger C, Greengard P, Strittmatter SM, Nairn AC, Lombroso PJ (2010) Genetic reduction of striatal-enriched tyrosine phosphatase (STEP) reverses cognitive and cellular deficits in an Alzheimer's disease mouse model. Proc Natl Acad Sci U S A 107, 19014-19019.

[84] Demars M, Hu YS, Gadadhar A, Lazarov O (2010) Impaired neurogenesis is an early event in the etiology of familial Alzheimer's disease in transgenic mice. J Neurosci Res $\mathbf{8 8}, 2103-2117$.

[85] Olsson A, Vanderstichele H, Andreasen N, De Meyer G, Wallin A, Holmberg B, Rosengren L, Vanmechelen E, Blennow K (2005) Simultaneous measurement of betaamyloid(1-42), total tau, and phosphorylated tau (Thr181) in cerebrospinal fluid by the XMAP technology. Clin Chem 51, 336-345.
[86] Brouillette J (2014) The effects of soluble Abeta oligomers on neurodegeneration in Alzheimer's disease. Curr Pharm Des 20, 2506-2519.

[87] Brouillette J, Caillierez R, Zommer N, Alves-Pires C, Benilova I, Blum D, De Strooper B, Buee L (2012) Neurotoxicity and memory deficits induced by soluble low-molecular-weight amyloid-beta1-42 oligomers are revealed in vivo by using a novel animal model. J Neurosci 32, 7852-7861.

[88] Ferreira ST, Klein WL (2011) The Abeta oligomer hypothesis for synapse failure and memory loss in Alzheimer's disease. Neurobiol Learn Mem 96, 529-543.

[89] Giacobini E, Gold G (2013) Alzheimer disease therapymoving from amyloid-beta to tau. Nat Rev Neurol 9, 677686.

[90] Drechsel DN, Hyman AA, Cobb MH, Kirschner MW (1992) Modulation of the dynamic instability of tubulin assembly by the microtubule-associated protein tau. $\mathrm{Mol}$ Biol Cell 3, 1141-1154.

[91] Witman GB, Cleveland DW, Weingarten MD, Kirschner MW (1976) Tubulin requires tau for growth onto microtubule initiating sites. Proc Natl Acad Sci U S A 73, 4070-4074.

[92] Guo JL, Lee VM (2011) Seeding of normal Tau by pathological Tau conformers drives pathogenesis of Alzheimer-like tangles. J Biol Chem 286, 15317-15331.

[93] Tapiola T, Alafuzoff I, Herukka SK, Parkkinen L, Hartikainen P, Soininen H, Pirttila T (2009) Cerebrospinal fluid beta-amyloid 42 and tau proteins as biomarkers of Alzheimer-type pathologic changes in the brain. Arch Neurol 66, 382-389.

[94] Kremer A, Louis JV, Jaworski T, Van Leuven F (2011) GSK3 and Alzheimer's Disease: Facts and Fiction. Front Mol Neurosci 4, 17.

[95] Castro-Alvarez JF, Uribe-Arias A, Cardona-Gomez GP (2015) Cyclin-dependent kinase 5 targeting prevents betaAmyloid aggregation involving glycogen synthase kinase 3 beta and phosphatases. J Neurosci Res 93, 1258-1266.

[96] Wen Y, Planel E, Herman M, Figueroa HY, Wang L, Liu L, Lau LF, Yu WH, Duff KE (2008) Interplay between cyclin-dependent kinase 5 and glycogen synthase kinase 3 beta mediated by neuregulin signaling leads to differential effects on tau phosphorylation and amyloid precursor protein processing. J Neurosci 28, 2624-2632.

[97] Yu Y, Run X, Liang Z, Li Y, Liu F, Liu Y, Iqbal K, GrundkeIqbal I, Gong CX (2009) Developmental regulation of tau phosphorylation, tau kinases, and tau phosphatases. J Neurochem 108, 1480-1494.

[98] Coan G, Mitchell CS (2015) An assessment of possible neuropathology and clinical relationships in 46 sporadic amyotrophic lateral sclerosis patient autopsies. Neurodegener Dis 15, 301-312.

[99] Mitchell CS, Lee RH (2008) Pathology dynamics predict spinal cord injury therapeutic success. J Neurotrauma $\mathbf{2 5}$, 1483-1497.

[100] Mitchell CS, Lee RH (2012) Dynamic meta-analysis as a therapeutic prediction tool for amyotrophic lateral sclerosis. In Amyotrophic Lateral Sclerosis, http://www.intecho pen.com/books/amyotrophic-lateral-sclerosis/dynamic-m eta-analysis-as-a-therapeutic-prediction-tool-for-amyotro phic-lateral-sclerosis.

[101] Irvin CW, Kim RB, Mitchell CS (2015) Seeking homeostasis: Temporal trends in respiration, oxidation, and calcium in SOD1 G93A Amyotrophic Lateral Sclerosis mice. Front Cell Neurosci 9, 248. 
[102] Kim RB, Irvin CW, Tilva KR, Mitchell CS (2015) State of the field: An informatics-based systematic review of the SOD1-G93A amyotrophic lateral sclerosis transgenic mouse model. Amyotroph Lateral Scler Frontotemporal Degener 17, 1-14.

[103] Mitchell CS, Hollinger SK, Goswami SD, Polak MA, Lee RH, Glass JD (2015) Antecedent disease is less prevalent in amyotrophic lateral sclerosis. Neurodegener Dis 15, 109-113.

[104] Dolan PJ, Johnson GV (2010) The role of tau kinases in Alzheimer's disease. Curr Opin Drug Discov Devel 13, 595-603.
[105] Kimura T, Ishiguro K, Hisanaga S (2014) Physiological and pathological phosphorylation of tau by Cdk5. Front Mol Neurosci 7, 65.

[106] Reynolds CH, Betts JC, Blackstock WP, Nebreda AR, Anderton BH (2000) Phosphorylation sites on tau identified by nanoelectrospray mass spectrometry: Differences in vitro between the mitogen-activated protein kinases ERK2, c-Jun N-terminal kinase and P38, and glycogen synthase kinase-3beta. J Neurochem 74, 1587-1595.

[107] Tenreiro S, Eckermann K, Outeiro TF (2014) Protein phosphorylation in neurodegeneration: Friend or foe? Front Mol Neurosci 7, 42. 